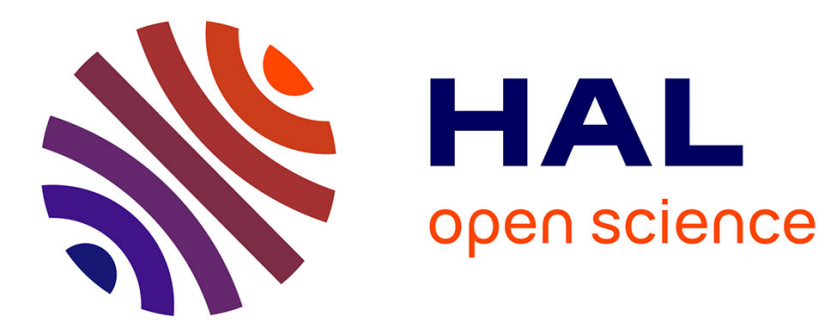

\title{
Pollutant source identification in a city district by means of a street network inverse model
}

Nabil Ben Salem, Lionel Soulhac, Pietro Salizzoni, Massimo Marro

\section{To cite this version:}

Nabil Ben Salem, Lionel Soulhac, Pietro Salizzoni, Massimo Marro. Pollutant source identification in a city district by means of a street network inverse model. International Journal of Environment and Pollution, 2014, 55 (1-2-3-4), pp.50-57. 10.1504/IJEP.2014.065904 . hal-01296878

\section{HAL Id: hal-01296878 https://hal.science/hal-01296878}

Submitted on 17 Apr 2019

HAL is a multi-disciplinary open access archive for the deposit and dissemination of scientific research documents, whether they are published or not. The documents may come from teaching and research institutions in France or abroad, or from public or private research centers.
L'archive ouverte pluridisciplinaire HAL, est destinée au dépôt et à la diffusion de documents scientifiques de niveau recherche, publiés ou non, émanant des établissements d'enseignement et de recherche français ou étrangers, des laboratoires publics ou privés. 


\title{
POLLUTANT SOURCE IDENTIFICATION IN A CITY DISTRICT BY MEANS OF A STREET NETWORK INVERSE MODEL
}

\author{
N. Ben Salem, L. Soulhac, P. Salizzoni, M. Marro \\ Laboratoire de Mécanique des Fluides et d'Acoustique, Université de Lyon, CNRS, Ecole Centrale de Lyon, INSA \\ Lyon, Université Claude Bernard Lyon I, Ecully, France
}

\begin{abstract}
:
This study presents the performances of an inverse modelling approach aiming in identifying position and emission rate of a localised pollutant source placed within a city district. To that purpose we combine wind tunnel experiments and an urban dispersion model. Experiments are performed in an idealised urban canopy, made up of regularly spaced blocks, and provide the pollutant concentration field downwind the source within the canopy. The urban dispersion model, named SIRANE, is an operational model that simulates the main mechanisms governing the pollutant transfer within a network of streets.
\end{abstract}

Keywords: atmospheric dispersion, accidental risk, inverse modelling, source identification, street network models, urban air pollution.

\section{INTRODUCTION}

The risk management of accidental atmospheric pollutant releases in a built environment is a major concern within both industrial sites and urban areas. To this purpose we need to identify rapidly the position and the strength of the pollutant source. This requires the application of inverse modelling techniques together with properly designed monitoring network. Previous authors (Lushi and Stockie, 2010; Chow et al., 2008) have combined inverse modelling techniques with different direct models, namely CFD codes and Gaussian dispersion models (Rudd et al., 2012). Both approaches show major limits for operational risk management in a built environment. CFD codes require long computation times, which are not consistent with crisis management. On the other side, the results of Gaussian model will be affected by significant errors due to an oversimplification of the velocity field, since these models are not able to simulate local effect due to obstacle wakes and streets channelling.

In this study we take advantage of recent advances in urban dispersion modelling, adopting a new direct operational model, named SIRANE (Soulhac et al., 2011) in order to simulate pollutant dispersion in idealised urban geometries, such as those investigated experimentally by Garbero et al. (2010). The aim is to identify a single stationary pollution source placed in a city district and whose position and flow rate are unknown, from a varying number of direct observations of pollutant concentration.

\section{WIND TUNNEL EXPERIMENTS}

The experimental measurements used in this study are those presented by Garbero et al. (2010) and carried within the wind tunnel of the Laboratoire de Mécanique des Fluides et d'Acoustique of the Ecole Centrale de Lyon.

The reduced scale model represents an idealised city district (Figure 1a), made up by parallelepipeds with squared section, with lateral size $L=250 \mathrm{~mm}$ and height $H=50 \mathrm{~mm}$ high, representing $20 \mathrm{~m}$ high buildings at the 1:400 scale.

Experiments were performed for different buildings configurations, obtained by varying the blocks spacing and the wind direction. A stationary source of a passive scalar $Q$ was placed at a street intersection of coordinates $X=Y=0$ and $Z=0.5 \mathrm{H}$. Ethane was used as passive tracer and its concentration downwind the source was measured by means of a Flame Ionisation Detector.

In the present study we focus a single configuration of obstacles, with regularly spaced buildings forming streets of width $W=H$ and a wind direction of $12.5^{\circ}$ (Fig.1a - dashed line). Concentration profiles measured within the streets for increasing distance from the source are shown in Figure 1a. The mean concentrations are expressed in a standard dimensionless form as $K(x, y, z)=\frac{C U_{H} L H}{Q} * 10^{-6}$, where $C$ is the measured mean concentration in ppm, and $U_{H}$ is the velocity at roof height (see Garbero et al, 2010).

\section{THE DIRECT MODEL: SIRANE}

SIRANE is an urban dispersion model (Soulhac et al., 2011) for operational purposes. The streets in a city district are represented as a network of connected street canyon segments and the overlying boundary layer flow is modelled by Monin-Obukhov similarity theory. The outputs of the model are concentrations in the external flow and spatially averaged concentrations within each street segment. The model contains three main mechanisms for transport within the urban canopy (Soulhac et al, 2013): turbulent transfer between the air in the street and the overlying boundary 
layer, channelling of pollutant along the street axes and pollutant exchanges at the street intersections. The dispersion of pollutants into the overlying boundary layer flow is treated by a Gaussian model.

The performances of the model have already been evaluated within real urban geometries, both against in situ data (Soulhac et al, 2012) and wind tunnel simulations (Carpentieri et al. 2012). Here we present some of the results obtained in a validation of the model in the idealized urban geometry. A comparison between model results and wind tunnel measurements is presented in Figure 1a. Main differences between the numerical results and experiments are due to the inability of SIRANE in reproducing the homogeneities of the pollutant concentrations within a single street canyon segment. Despite this main limit, Figure 1a shows an overall good agreement between the two sets of data.

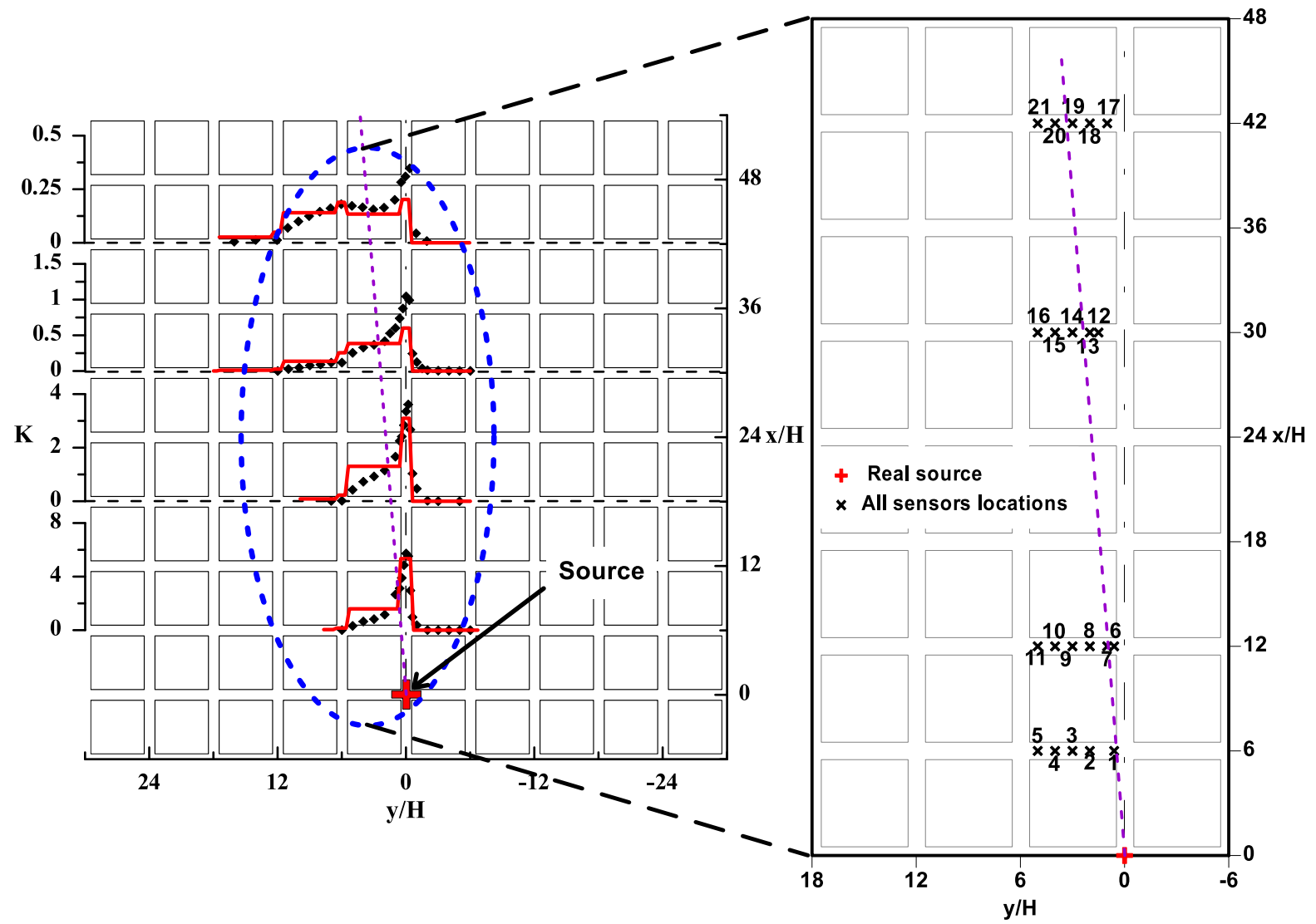

Fig. 1a. Comparison between experimental results (diamonds) and numerical results (lines) at different distances from the source, (placed at + ). The dashed line indicates the wind direction of the external wind $\left(12.5^{\circ}\right)$. Fig. 1b. Position of the receptors used in the inverse modelling.

\section{INVERSE MODEL}

The inverse model can lead to the identification of the position and the strength of a pollutant source Q, taking advantage of the linearity that links it to the concentrations $C$ at the receptors (Bocquet, 2010). We have thus to inverse a linear equation system

$$
C(m, 1)=\operatorname{ATC}(m, n) * Q(n, 1)
$$

with $m$ equations and $n$ unknowns. ATC (Atmospheric Transfer Coefficient) is the mathematical operator that models the physical mechanisms that are responsible for the dilution of the time averaged concentration in the atmosphere, and is here computed by applying the code SIRANE.

The inversion of the system (1) is simple when the problem is well posed in the sense of Hadamard (1923), i.e. it admits a unique solution which depends continuously on the data. Otherwise, we need specific optimization and resolution algorithms (Giacobbo et al., 2002; Menut et al., 2006; Rudd et al., 2012; Delle Monache et al., 2008; Khlaifi et al., 2009) such as the Gauss-Newton method, the genetic algorithm, the Bayesian method, the MCMC. In our inverse code, the inversion of (1) varies depending on the number of pollutant sources and on the availability of 
receptor concentrations. We are here particularly concerned with the case $m>n$ since the number of measurement is generally greater than that of the pollutant sources. In case that rank $(A T C)=n$ and that the problem is overdetermined, the system (1) has one solution that can be determined by minimising the cost function:

where the error is defined as e $\varepsilon=C-A T C * Q$.

$$
J=\frac{1}{2}\|\varepsilon\|^{2}=\frac{1}{2} \varepsilon^{T} \varepsilon
$$

\section{SOURCE STRENGTH}

Firstly we aim in estimating the flow rate of the source with a known position. We analyse the sensitivity of the inverse model depending on the number and the positions of the receptors.

\section{Sensitivity to the number of the receptors}

We show results related to two different receptors configurations. Each configuration consists of four sensors placed in different street canyons, referred to as Configuration $1=\{1 ; 8 ; 15 ; 18\}$ and Configuration $2=\{2 ; 8 ; 13 ; 18\}$. It is worth mentioning there is no particular strategy behind the choice of these configurations, which are therefore used here only as test cases. Further work is needed in order to evaluate accurately a larger set of configurations.

For each of the two configuration we evaluate the relative error, defined as $E(\%)=\left(\left(Q_{\text {true }}-Q_{\text {est. }}\right) * 100\right) / Q_{\text {true. }}$, for increasing number of receptors (Tab. 1) used to inverse the system (1). As expected, results show that the relative error rate is a decreasing function of the number of sensors used in the inversion. However, it is worth mentioning that the error in the estimate of the source emission is very sensitive to the position of the receptors within the streets. Table 1 shows that error estimates provided by Configuration 2 are significantly smaller than those obtained for Configuration 1, for any number of the receptor. For example, we can notice that a single receptor in Configuration 2 provides an error $(\mathrm{E}=23.9 \%)$ four times lower than that obtained in Configuration $1(\mathrm{E}=104.9 \%)$, even if the two sensors are located in the same street.

Tab. 1. Relative error rate estimates for two receptor configurations.

\begin{tabular}{lllll}
\hline $\begin{array}{l}\text { Number of } \\
\text { measurements }\end{array}$ & Conf. 1 & \multicolumn{3}{c}{ Conf. 2 } \\
\hline 1 & Receptors & $\mathrm{E}_{\mathrm{Q}}(\%)$ & Receptors & $\mathrm{E}_{\mathrm{Q}}(\%)$ \\
2 & $\{1\}$ & 104.9 & $\{2\}$ & 23.9 \\
3 & $\{1 ; 8\}$ & 52.3 & $\{2 ; 8\}$ & 15.9 \\
4 & $\{1 ; 8 ; 15\}$ & 35.0 & $\{2 ; 8 ; 13\}$ & 6.3 \\
\hline
\end{tabular}

\section{Sensitivity to the position of the receptors}
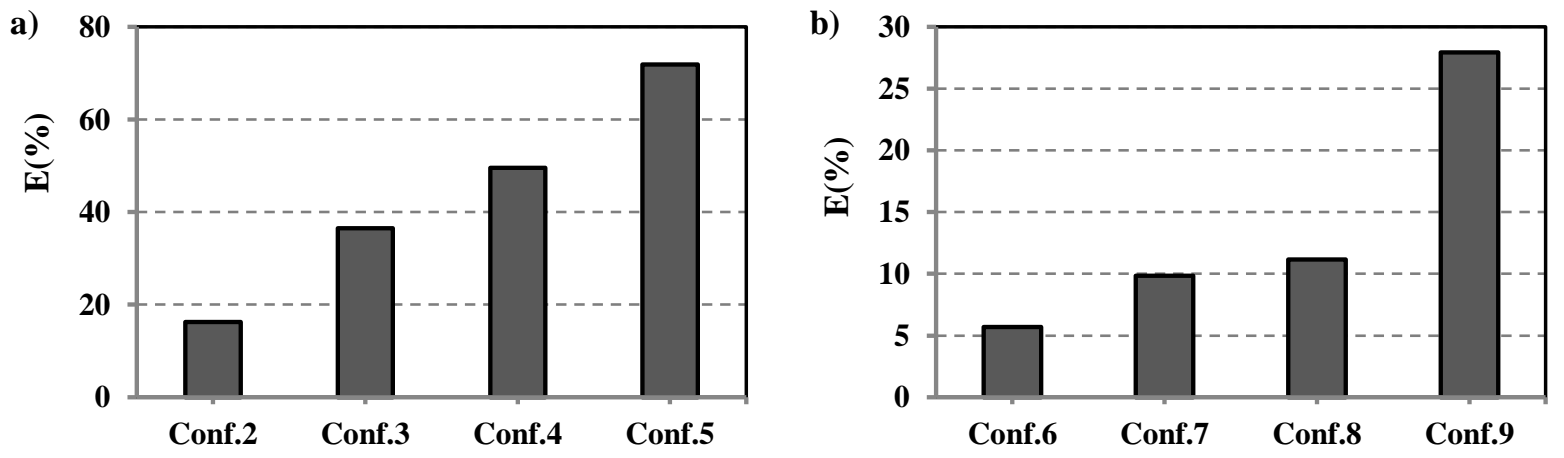

Moving receptors laterally from the plume centreline

Fig. 2. Relative error rate estimates for each inversion configuration - Fig.(2a.): Inversion using four sensors located in different streets:,- Fig.(2b.) : Inversion with 4 sensors located in a same street.

Secondly, we adopt different configurations made up of four receptors. We keep unaltered the number of the receptors and we vary their position in the network (Fig. 1b.) in two different ways:

a) we locate the receptors in four different streets, and we vary their position within these streets: Conf. $2=\{2 ; 8 ; 13 ; 18\}$, Conf. $3=\{3 ; 9 ; 14 ; 19\}$, Conf. $4=\{4 ; 10 ; 15 ; 20\}$, Conf. $5=\{5 ; 11 ; 16 ; 21\}$ 
b) we locate the four in a same street, and we vary the street within which they are located: Conf. $6=\{1 ; 2 ; 3 ; 4\}$, Conf. $7=\{6 ; 7 ; 8 ; 11\}$, Conf. $8=\{12 ; 13 ; 14 ; 15\}$, Conf. $9=\{18 ; 19 ; 20 ; 21\}$

In the case a), as Figure 2a shows, the error increases as we move laterally away from the centre of mass of the plume (which is roughly indicated by the dotted line in Figure 1a).

In the case b), the error increases for increasing distances from the source. Anyway it is worth noting that, in case b), even in the worst case tested, referred to as Conf. 9, the error does not exceed 30\%. This is significantly less that obtained for the case a) and is directly related to the characteristic of the direct model SIRANE, that predict only spatially averaged concentration within the streets.

\section{SOURCE LOCATION}

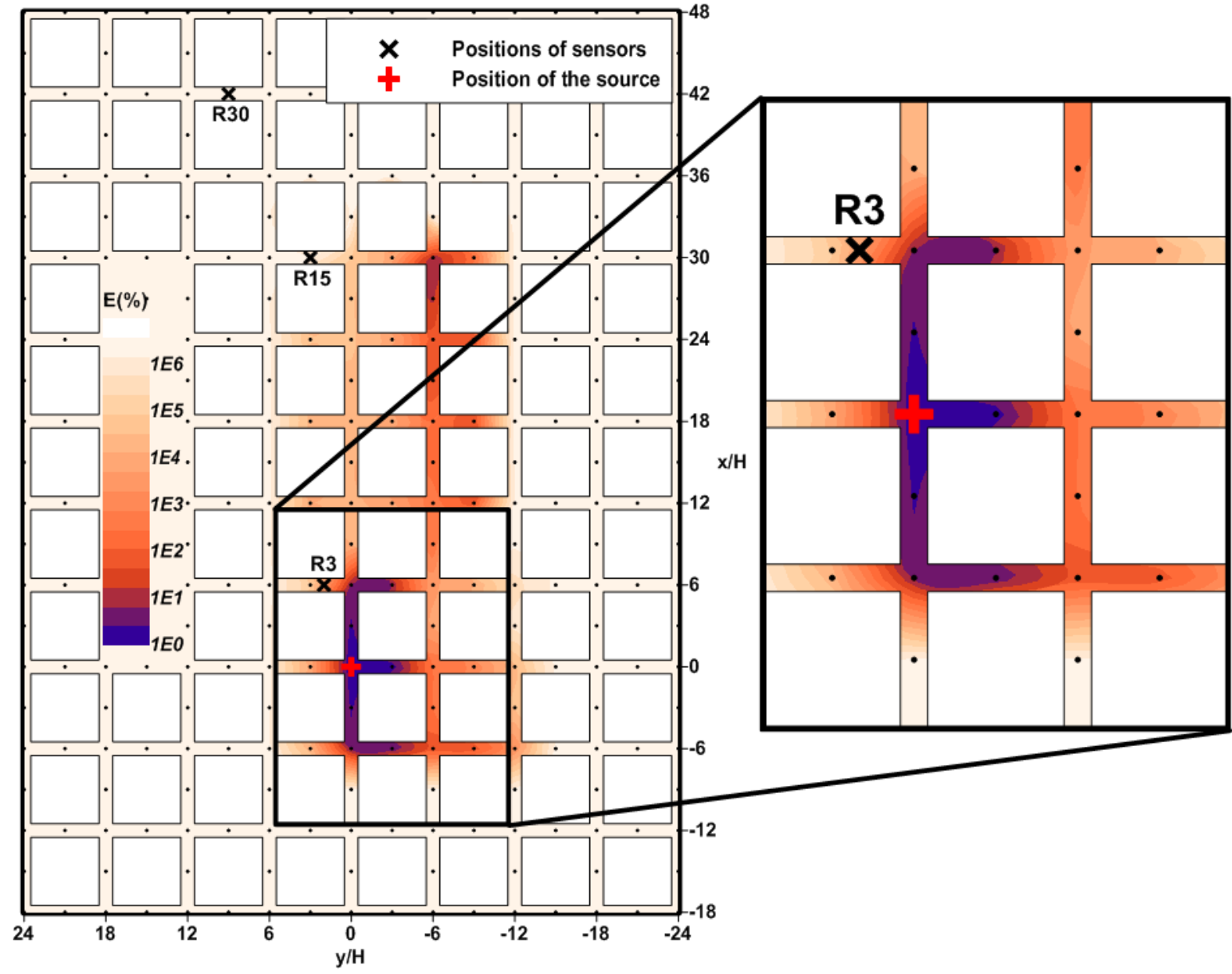

Fig. 2. Iso-contours of the error estimates for different source positions, indicated by dots. The zoom shows details of the error in the region of the real source location.

Finally we apply a direct method algorithm to identify rapidly the position and the emission rate (strength) of the source. The algorithm tests different source locations, distributed over a regular mesh and selects the one thta minimizes a cost function, defined as:

$$
\mathrm{J}=\frac{1}{\mathrm{~N}} \sum_{\mathrm{t}=1}^{\mathrm{T}} \max \left(\left|\frac{\mathrm{Q}_{\text {est. }}^{\mathrm{t}}\left(\mathrm{R}_{\mathrm{i}}\right)-\mathrm{Q}_{\text {est. }}^{\mathrm{t}}\left(\mathrm{R}_{\mathrm{j}}\right)}{\mathrm{Q}_{\text {est. }}^{\mathrm{t}}\left(\mathrm{R}_{\mathrm{i}}\right)}\right| * 100\right)_{\mathrm{i} \neq \mathrm{j}}
$$

where $Q_{\text {est. }}^{t}\left(R_{i}\right)$ is emission rate estimated by the receptor $R_{i}$ and $N$ is the number of receptors. This method requires at least three different receptors, which have been placed as indicated in Fig. 3. For each potential positions of 
source, we compare the results of the inversion of emission rate from the observations in three receptors and we choose the position providing the minimal error. Results show that the inverse model is able to locate reliably the source position (Fig.3) and determines the emission rate with an error that does not exceed $10 \%$. A sensitivity analysis, whose results are not explicitly given here, shows that the accuracy in the source location is not very sensitive to the position of the three receptors, provided that they are placed downwind the source.

\section{CONCLUSIONS AND PERSPECTIVES}

We presented a few tests of inversion to identify position and emissions rate of a localised pollutant source located within a city district, combining the street network dispersion model SIRANE and wind tunnel measurements. The inverse model allows us to identify the source position with high accuracy with a reduced number of receptors. Accurate estimates can be achieved with only three receptors, provided that these are placed down-wind the source. The error in the predictions the source flow rate are higher and much more sensitive to the number of receptor and on their location within the district (Akçelik et al. , 2003; Rudd et al. , 2012; Khlaifi et al., 2009). Future work will concern the extension of this analysis to different wind direction and obstacles layout, and to time-dependent pollutant emissions.

\section{REFERENCES}

Akçelik, V., G. Biros, O. Ghattas and K. R. Long, 2003: A variational finite element method for source inversion for convective-diffusive transport: Finite elements in analysis and design, 39,683-705.

Bocquet, M., 2010 : Modélisation inverse des sources de pollution atmosphérique accidentelles : progrès récents. Pollution atmosphérique ; septembre 2010,151-160.

Carpentieri, M., P. Salizzoni, A. Robins, L. Soulhac, 2012: Evaluation of a neighbourhood scale, street network dispersion model through comparison with wind tunnel data: Environmental Modelling \& Software, 37, $110-124$.

Chow, F. K., B. Kosovic and S. Chan, 2008: Source inversion for contaminant plume dispersion in urbain environments using building-resolving simulations: Journal of applied meteorology and climatology, 47, 1553-1572.

Delle Monache, L., J. Lundquistand, B. Kosovic, G. Johannesson, K. Dyer, R. Aines, F. Chow, R. Belles, W. Hanley, S. Larsen, G. Loosmore, J. Nitao, G. Sugiyama and P. Vogt, 2008: Bayesian inference and Markov Chain Monte Carlo sampling to reconstruct a contaminant source on a continental scale: Journal of Applied Meteorology and Climatology, 47, 2600-2613.

Garbero, V., P. Salizzoni, L. Soulhac and P. Méjean, 2010: Experimental study of pollutant dispersion within a network of streets : Boundary Layer Meteorology,136(3),457-487.

Giacobbo, F., M. Marseguerra and E. Zio, 2002: Solving the inverse problem of parameter estimation by genetic algorithms: the case of a groundwater contaminant transport model. Annals of nuclear energy, 29(8), $15 \mathrm{p}$.

Hadamard, J., 1923: Lectures on Cauchy's Problem in Linear Partial Differential Equations, Yale University Press,314 pp.

Khlaifi, A., A. Ionescu and Y. Candau, 2009: Pollution source identification using a coupled diffusion model with a genetic algorithm: Mathematics and computers in simulation, 79, 3500-3510.

Lushi, E. and J. M. Stockie, 2010: An inverse Gaussian plume approach for estimating atmospheric pollutant emissions from multiple point sources: Atmos. Environ., 44, 1097-1107.

Menut L., I. Pison, L. Deguillaume, M. Beekmann and N. Blond, 2006: Optimisation des émissions par modélisation inverse. Rapport final de l'institut Pierre Simon Laplace, $90 \mathrm{pp}$.

Rudd, A. C., A. G. Robins, J. J. Lepley and S. E. Belcher, 2012: An inverse method for determining source characteristics for emergency response applications. Boundary-layer meteorology, DOI: 10.1007/s10546012-9712-y.

Soulhac, L., P. Salizzoni, F. X. Cierco and R. J. Perkins, 2011: The model SIRANE for atmospheric urban pollutant dispersion; PART I, presentation of the model: Atmospheric Environment., 45, 7379-7395.

Soulhac, L., P. Salizzoni, P. Mejean, D. Didier and I. Rios, 2012: The SIRANE model for atmospheric urban pollutant dispersion: PART II, validation of the model on a real case study. Atmospheric Environment, 49, 320-337.

Soulhac, L., P. Salizzoni, P. Mejean and R. J. Perkins, 2013 : Parametric laws to model urban pollutant dispersion with a street network approach: Atmospheric Environment, 67, 229-24. 